\section{Anthrax Vaccines}

Miroslav Splino, MD, DSc;* Jiri Patocka MD, DSc;† Roman Prymula, MD, PhD;*

Roman Chlibek, MD, PhD*

SUMMARY: Anthrax, an uncommon disease in humans, is caused by a large bacterium, Bacillus anthracis. The risk of inhalation infection is the main indication for anthrax vaccination. Pre-exposure vaccination is provided by an acellular vaccine (anthrax vaccine adsorbed or AVA), which contains anthrax toxin elements and results in protective immunity after 3 to 6 doses. Anthrax vaccine precipitated (AVP) is administered at primovaccination in 3 doses with a booster dose after 6 months. To evoke and maintain protective immunity, it is necessary to administer a booster dose once at 12 months. In Russia, live spore vaccine (STI) has been used in a two-dose schedule. Current anthrax vaccines show considerable local and general reactogenicity (erythema, induration, soreness, fever). Serious adverse reactions occur in about $1 \%$ of vaccinations. New second-generation vaccines in current research programs include recombinant live vaccines and recombinant sub-unit vaccines.

$\mathrm{T}$ The anthrax bacillus (Bacillus anthracis) was the first bacterium shown to be the cause of a disease when in 1877 Robert Koch grew the organism in pure culture, demonstrated its ability to form endospores, and produced experimental anthrax by injecting it into animals. At that time, 125 years ago, anthrax was significant mainly as an economically damaging disease of domesticated animals. Today, anthrax is an important agent of biological terrorism and a threat to civilization. ${ }^{1,2,3}$

Inhalation anthrax is the most lethal form. The incubation period following inhalation of spores lasts for 1 to 7 days, possibly up to 60 days. Pulmonary anthrax develops after inhalation of a spore aerosol, mainly during industrial processing of contaminated wool, hair, or hides. The initial symptoms may resemble a common cold: sore throat, fever, and muscle ache. The symptoms progress after several days to severe breathing distress and shock. Direct transmission of pulmonary anthrax from man to man has not been proved. At the beginning of the 1950s, offensive research with B. anthracis led to preparation of anthrax spores for possible use as a biological weapon because of its specific biological properties. ${ }^{4}$

An outbreak of inhalation anthrax occurred in Sverdlovsk (in the former Soviet Union) in 1979. The outbreak followed a random discharge of anthrax spores into the atmosphere by a research facility involved in "weaponizing anthrax." It was reported that the first clinical symptoms appeared 43 days after the initial exposure. The exact date of exposure was only estimated and never exactly confirmed. The modal incubation period in that outbreak was reported to be 9 to 10 days. ${ }^{9}$ After the Gulf War in 1991, Iraq was convicted of conducting offensive research, production, weaponizing and storage of anthrax in rockets and bombs. ${ }^{6}$ In the US, terrorists used anthrax after 11 September 2001. The first inhalation case was reported on 4 October 2001, and the last one on 31 October $2001 .^{7}$

The possibility of terroristic misuse of anthrax spores presupposes deliberate primary or secondary aerosolization of B. anthracis spores. The inhalation dose for anthrax spores in humans is not precisely known. The estimated infectious dose by the respiratory route required to cause inhalation anthrax in humans is 8000 to 50000 spores, based on data from studies on primates. ${ }^{8}$ Aerosol particles larger than 5 microns quickly subside, but there is the possibility of secondary aerosol formation. Smaller aerosol particles ( 1 to 5 microns in diameter) behave as a gas and persist in the environment without settling. The reported incubation period for inhalation anthrax ranges from 1 to 43 days. ${ }^{9}$
From the *Department of Epidemiology and + Department of Toxicology, Military Medical Academy, Hradec Kralove, Czech Republic

Correspondence to:

Jiri Patocka, MD

Department of Toxicology

Military Medical Academy

Hradec Kralove

Czech Republic

patocka@pmfbk.cz

Accepted for publication:

May 2004

Ann Saudi Med 2005;25(2):143-149 
The incubation period after inhalation of $B$. anthracis spores is related to the dose. Post-exposure prophylaxis during an outbreak may prolong the incubation period. Experimental results in laboratory animals suggest that $B$. anthracis spores convert into a vegetative form in the host for several weeks postinfection. The inhaled spores in the alveolar spaces of the lungs are phagocytized by pulmonary macrophages. Otherwise, they gradually germinate and multiply. Prophylactic administration of antibiotics does not affect the germinating spores, but only the vegetative germs of $B$. anthracis. After discontinuation of antibiotics in the presence of non-germinated spores (if sufficiently numerous), a new germination occurs, gradual impairment of immune mechanisms appears, and anthrax develops. The lethality in untreated inhalation anthrax reaches $86 \%$ to $97 \% .{ }^{10}$

The toxigenic properties of $B$. anthracis were discovered in 1954. Prior to that time, it was assumed that death was due to blockage of the capillaries by a large amount of spores. However, it was experimentally shown that only about $3 \times 10^{6}$ cells $/ \mathrm{mL}$ are necessary to cause the death of an animal. These observations led to the conviction that a specific anthrax exotoxin plays a major role in the pathogenesis of disease. Death from anthrax in humans or animals frequently occurs suddenly and unexpectedly. The level of lethal toxin in the circulation rapidly increases quite late in the disease, and closely parallels the concentration of organisms in the blood.

The production of anthrax toxin is mediated by plasmid pX01 (110 MDa). ${ }^{11}$ Anthrax toxin is not a single compound, but a complex substance composed of three antigenically distinct proteins. These are termed (for historic reasons) factor I, edema factor $(\mathrm{EF})$, factor II, protective antigen (PA) and factor III, lethal factor (LF). ${ }^{12}$ Apart from their antigenicity, each of the three factors exhibits no significant biological activity in an animal. However, combinations of two or three of the toxin components yield a lethal combination.

\section{Protective Immunity}

Worldwide, anthrax among livestock is controlled through vaccination programs. A live unencapsulated variant of $B$. anthracis, strain Stern, has been used in veterinary practice to protect livestock since 1939. ${ }^{13,14}$ This vaccine was used as a standard for a long time. The induced immunity is short-termed and persists for 1 to 2 years. New experimental knowledge led to the preparation of more effective acellular vaccines. The sterile edema fluid of anthrax lesions was used for protective immunity in laboratory animals. Further studies of $B$. anthracis culture filtrates accelerated the preparation of human anthrax vaccine in the USA and in Europe. ${ }^{15}$

The first vaccine for humans (acellular vaccine) was developed in 1954. It was prepared from an aerobic $B$. anthracis culture filtrate adsorbed on aluminum potassium sulfate. ${ }^{16}$ The vaccine was tested on a monkey model. It exhibited low reactivity and short-term adverse events. During 1957 to 1960, the vaccine was improved through selection of a suitable B. anthracis strain with high production of the protective antigen (PA) and use of aluminum hydroxide as adjuvant. ${ }^{15}$ The vaccine was approved for using in the United States as anthrax vaccine adsorbed (AVA) in 1965. Specific correlates for immunity against anthrax have not been identified. A humoral and cellular response against protective $B$. anthracis antigen (PA) is critical to protection against disease. ${ }^{17}$

\section{Vaccine Characterization}

AVA, an anthrax vaccine licensed in the United States, is produced by BioPort Corporation of Lansing, Michigan. The production strain, known as V 770-NP1-R, is toxigenic and nonencapsulated. It is prepared from a cell-free filtrate of $B$. anthracis culture that contains neither dead, nor live bacteria. The filtrate is adsorbed onto aluminum hydroxide adjuvant (Amphogel), and contains all three toxin components: protective antigen (PA), lethal factor $(\mathrm{LF})$, and edema-forming protein (EF). The vaccine is indicated for pre-exposure prophylaxis. The primary vaccination consists of three subcutaneous injections at 0,2 and 4 weeks, and three booster vaccinations at 6,12 , and 18 months. To maintain immunity, the manufacturer recommends an annual booster injection. The basis for the schedule of vaccinations is not well defined. Mild local reactions occur after the vaccination: erythema, edema, and induration smaller than $30 \mathrm{~mm}$ appears after $20 \%$ of vaccinations. Moderate local reactions, defined as edema and induration of 30 to $120 \mathrm{~mm}$, occurred after $3 \%$ of vaccinations. Severe local reactions occurred after $1 \%$ of vaccinations. ${ }^{18}$

The vaccine efficacy of AVA was tested during several animal studies and vaccine-controlled trials in humans. ${ }^{19}$ Indirect hemagglutination was used to determine antibodies. Seroconversion reached $83 \%$ two weeks after the first dose and $91 \%$ after the two or more doses. Approximately $95 \%$ of vaccinees seroconvert with a fourfold rise in anti-PA IgG titres after three doses. But the precise correlation between 
antibody titre and protection against infection is not defined. ${ }^{17}$ Data from the macaque model (Rhesus monkeys) indicate that after administration of AVA vaccine, protective immunity is induced that protects monkeys against inhalation by limiting the dose of B. anthracis spores. ${ }^{19}$

The AVP vaccine (anthrax vaccine precipitated) is licensed in Great Britain. It was developed by the Centre for Applied Microbiology and Research at Porton Down, Salisbury, using an avirulent toxigenic, non-capsulating (pXO1+/pXO2-) 34F2 strain of Bacillus anthracis originally isolated by Sterne in 1937. It contains protective antigen PA and lethal factor LF. The main indication for using the vaccine is epidemiological risk of inhalation infection by $B$. anthracis spores. A UK product license was granted for the vaccine in 1979.

The AVP vaccine is administered in a three-dose primary regimen 3 weeks apart, followed by the fourth dose after an interval of 6 months. Booster doses should be given annually. Its simultaneous administration with other vaccines is not generally recommended. The active ingredient in the vaccine is a sterile filtrate of alum-precipitated anthrax antigens in solution for injection. The other ingredients are aluminum potassium sulphate, sodium chloride, and purified water. The preservative is thimerosal $(0.005 \%)$. Immunization by the vaccine induces production of $\mathrm{IgG}$ antibodies, which guarantees good immunogenicity. No serious side effects have been reported. Reactions are uncommon, but occasionally a mild rash or swelling at the site of injection, or even at the site of an earlier injection may occur and last for a couple of days. More rarely, swollen glands, mild fever, flu-like symptoms, rash, itching, or other allergic reactions may occur. The occurrence of a reaction after the first injection of the vaccine does not necessarily indicate a pre-disposition to subsequent reactions upon further injections.

In the Czech Republic, the AVP vaccine was used for pre-exposure vaccination of chemical battalion troops sent to Kuwait in 2002. Altogether 353 persons were immunized by two doses intramuscularly. After the vaccination, rest without physical stress was recommended. On the second or third day, pains at the site of the injection, muscle and joint pains, increased fatigue, and subfebrile temperatures up to $38 \mathrm{oC}$ occurred in the vaccinees. Higher reactogenicity was observed in 25 persons. ${ }^{20}$

The development of anthrax human vaccine in the former Soviet Union began in the military laboratories of the Sanitary Technical Institute (STI) at Kirov around 1935 by isolation of two avirulent non-capsulated ST- 1 and ST- 3 strains derived from a virulent strain. A live spore vaccine was prepared in $30 \%$ glycerol-saline solution. The protective efficacy was tested in guinea pigs after vaccination of $3 \mathrm{X} 107$ spores applied subcutaneously. After three weeks, it was augmented by a subcutaneous $\mathrm{LD}^{50}$ dose of a virulent strain and the protection reached $60 \% .{ }^{21}$

After World War II, the above-mentioned strains of suspended live spores in 50\% glycerol-physiological solution were used for human vaccine development. The vaccine was recommended for administration through scarification and for subcutaneous administration. ${ }^{22}$ During 1943 to 1950 , the testing of a spore vaccine was carried out in 3500 volunteers. The protective potency of the vaccine was not specifically defined. The vaccine was designated as safe and immunogenic. Adverse reactions were not specifically defined. During 1951 to 1952, a field trial was carried out in 14 endemic anthrax localities of the Moldavian Republic. Altogether 141663 persons 14 to 60 years old were vaccinated: 92150 by scarification and 49513 subcutaneously. A control group of 416000 persons were from the same region. In persons vaccinated by scarification (1010 persons), a temperature of $38^{\circ} \mathrm{C}$ was recorded in $0.3 \%$ on the first and second day without other significant symptoms. After subcutaneous vaccination of the tested persons (5402), local erythema, induration, and increased temperature were observed in $0.26 \%$ of persons. In the vaccinated groups, the cutaneous type of anthrax was recorded in the range of 2.1/100 000 vaccinated persons/year compared with 11.3/ 100 000/year in the control group. The difference was statistically significant. ${ }^{21}$ The published data on side effects and adverse reactions is extremely small. The live spore vaccine received a license for scarification in 1953 and for subcutaneous administration in 1959. In 1960 in the former Soviet Union, two million persons were vaccinated yearly with one dose by scarification or subcutaneously, and after 1 year a booster dose was administered.

The human anthrax live spore vaccine for aerogenic administration (ST-1 and ST-3) was tested by Alexandrov et al. ${ }^{23}$ The inhalation vaccination was carried out in a group of 263 adult volunteers. The inhalation dose consisted of 15 to $640 \mathrm{X} 10^{6}$ live spores. The volunteers were observed for 7 to 21 days. Adverse reactions, including increased temperature, were not recorded and the vaccinated persons worked according their daily routine. During 1973 to 1975 in the former Soviet Union, repeated studies on the 
efficacy of the human ST-1 vaccine were carried out using subcutaneous administration by $P e d-O-J e t$ and scarification in Central Asia. Ten thousand persons were observed with fifty thousand people from the same region forming the control group. The protective effect of the vaccinated in comparison with the control group was statistically highly significant. The live spore anthrax vaccine STI-1 is characterized as safe without adverse reactions with good preventive protection. As the best variant for immunization praxis, Russian experts recommended applying chemovaccine at the beginning of the vaccination and applying booster doses by means of a live vaccine. ${ }^{21}$ Despite this, we think that it is necessary to take into consideration the use of a live spore vaccine from the standpoint of possible risks. Table 1 summarizes the characteristics of anthrax vaccines developed for preexposure vaccination.

\section{Pre-exposure Vaccination}

Routine vaccination is indicated for persons engaged in work involving production quantities or concentrations of B. anthracis cultures, and for persons in whom it is impossible to eliminate the risk of inhalation infection, i.e., those working at risk of high contamination by anthrax from animal products: furs, bone meal, or wool. ${ }^{24}$ The limiting factor is the incidence of anthrax in animals and a calculable risk assessment. Pre-exposure vaccination should be based on a calculable risk assessment, but it cannot be predetermined objectively. Pre-exposure vaccination is considered in special military units and other selected population groups for which a calculable risk factor can be assessed. ${ }^{19}$

On 29 June 2002, the Pentagon shifted the anthrax vaccine to civilian use, and a new strategy for anthrax vaccination was reported. The Pentagon started to vaccinate all persons who will work at least 15 days/year in regions with possible occurrence of anthrax: the Korean Peninsula, Persian Gulf countries, or Afghanistan. The Department of Health and Human Services will create a national vaccine reserve that could be used, in case of a terrorist attack, for police officers, fire fighters, rescue squads, and others.

\section{Adverse Reactions}

The US pays ongoing attention to adverse reactions of the AVA vaccine. The data from the Vaccine

Table 1. Studies of anthrax vaccines for pre-exposure prophylaxis.

\begin{tabular}{|c|c|c|c|c|}
\hline Vaccine & $\begin{array}{l}\text { Number of persons } \\
\text { in field trial }\end{array}$ & $\begin{array}{l}\text { Route of administration } \\
\text { and dose }\end{array}$ & $\begin{array}{l}\text { Reactogenicity (R) } \\
\text { and immunogenicity (I) } \\
\text { if reported }\end{array}$ & Year of introduction \\
\hline $\begin{array}{l}\text { Live spore vaccine (ST1, } \\
\text { ST3), experimental vaccine, } \\
\text { USSR }\end{array}$ & 3500 volunteers & $\begin{array}{l}\text { Scarification or } \\
\text { subcutaneous } \\
\left(1.3 \times 10^{6} \text { spores }\right)\end{array}$ & $\begin{array}{l}\text { R: Safe, lack of local } \\
\text { side effects } \\
\text { I: Unknown }\end{array}$ & $\begin{array}{l}1950 \\
\text { Shlyakhov and Rubinstein }{ }^{21} \\
\text { Romanov }^{36}\end{array}$ \\
\hline $\begin{array}{l}\text { Live spore vaccine (ST1), } \\
\text { USSR }\end{array}$ & 107000 & $\begin{array}{l}\text { Ped-0-Jet (52 763) } \\
\text { Scarification (54 522) }\end{array}$ & $\begin{array}{l}\text { R: Local side effects } \\
\text { I: Good efficacy }\end{array}$ & $\begin{array}{l}\text { 1973-1975 } \\
\text { Romanov }^{36}\end{array}$ \\
\hline $\begin{array}{l}\text { Live, dry vaccine (ST1), } \\
\text { Russia (licensed 1993) }\end{array}$ & $\begin{array}{l}\text { Unknown, in use for } \\
14 \text { to } 60 \text { years }\end{array}$ & $\begin{array}{l}\text { Subcutaneous dose: } \\
60 \times 10^{6} \text { spores } / 0.5 \mathrm{~mL} \\
\text { Scarification dose: } \\
600 \text { million spores } / 0.5 \mathrm{~mL} \\
\text { Initial immunization: } \\
2 \text { times daily within } 20-30 \\
\text { days } \\
\text { Revaccination: } \\
\text { Once every year }\end{array}$ & $\begin{array}{l}\text { R: Local reaction after } \\
24-48 \mathrm{~h} \text {, hyperemia, small } \\
\text { infiltrate with formation of } \\
\text { yellowish scab (up to } 50 \mathrm{~mm} \text { ) }\end{array}$ & $\begin{array}{l}1993 \\
\text { Shlyakhov and Rubinstein }{ }^{21}\end{array}$ \\
\hline $\begin{array}{l}\text { Anthrax vaccine absorbed } \\
\text { (AVA), USA, FDA approved, } \\
1970^{*}\end{array}$ & $\begin{array}{l}69000 \text { soldiers } \\
\text { (more than } 1620793 \text { doses) }\end{array}$ & $\begin{array}{l}\text { Interval: 0, 2, } 4 \text { weeks, } \\
\text { booster 6, 12, } 18 \text { months } \\
\text { Dose: } 0.5 \mathrm{~mL} \text { IM, booster } \\
\text { annually }\end{array}$ & $\begin{array}{l}\text { R: Erythema, induration } \\
30 \mathrm{~mm} \text { and greater, muscle } \\
\text { pain, seroconversion after } \\
3 \text { doses } 95 \% \text { IgG }\end{array}$ & $\begin{array}{l}1998-2002 \\
\text { Lange et al. }^{36}\end{array}$ \\
\hline $\begin{array}{l}\text { Anthrax vaccine } \\
\text { precipitated (AVP), UK, } \\
\text { licensed } 1979\end{array}$ & Unknown & $\begin{array}{l}3 \text { doses in } 3 \text { weeks, } 4 \text { th dose } \\
\text { after } 6 \text { months, booster } \\
\text { annually, } 0.5 \mathrm{~mL} \mathrm{IM}\end{array}$ & $\begin{array}{l}\text { R: rash, swelling, site } \\
\text { infection, mild fever, flu-like } \\
\text { symptoms }\end{array}$ & $\begin{array}{l}2000-2002 \\
\text { Baillie et al. }{ }^{38}\end{array}$ \\
\hline $\begin{array}{l}\text { Anthrax vaccine absorbed } \\
\text { (AVA), USA }\end{array}$ & $\begin{array}{l}\text { More than } 500000 \text { USA } \\
\text { military personel }\end{array}$ & $\begin{array}{l}\text { Interval: } 0,2,4 \text {, weeks, } \\
\text { booster } 6,12,18 \text { month } \\
\text { Dose: } 0.5 \mathrm{~mL} \text { IM, } \\
\text { booster annually }\end{array}$ & $\begin{array}{l}1841 \text { reports describing } 3991 \\
\text { adverse events ( } 9.4 \text { reports/ } \\
10000 \text { doses of AVA) }\end{array}$ & $\begin{array}{l}1998-2003 \\
\text { Sever et al. }\end{array}$ \\
\hline
\end{tabular}

*ProMED-mail. Anthrax vaccine, safety and efficacy. ProMED-mail 2002; 9 Mar: 20020309.3715. www.promedmail.org 
Adverse Event Reporting System (VAERS) ${ }^{24}$ shows that 1859000 anthrax vaccine doses were distributed in the US from January 1990 until the end of August 2000. The VAERS registered 1544 adverse reactions of which 76 were severe, including two deaths. Approximately $70 \%$ of reported reactions occurred in persons under the age of 40. A broad range of health effects were assessed in a cohort of 601 health care personnel, immunized with AVA as a military occupational health requirement, to evaluate adverse events both qualitatively and quantitatively. Active surveillance showed that localized reactions were common and occurred more often in women than men. Five patients were reported to the VAERS, but only one event could be definitively attributed to immunization, a large localized reaction. AVA is relatively reactogenic but there are no serious adverse health effects due to immunization. ${ }^{27}$ In attempts to explain the Persian Gulf War (PGW) syndrome, deployed veterans vaccinated for anthrax were examined, but existing scientific evidence does not support an association between anthrax vaccine and PGW illnesses. ${ }^{28}$ In March 2002, the Pentagon asked the Institute of Medicine, an independent research organization in the US to carry out a study on the safety and efficacy of AVA vaccine, which represented the basis for using the vaccine in the military. The study did not confirm the statement of vaccinated soldiers that administration caused health impairment. However, the vaccine proved to be "far from optimal". The Pentagon accepted the results, started the military immunization program, and approved research by the Department of Defense to accelerate the development of a new vaccine (within 5 years).

Because of the considerable local reactogenicity of the original six-dose vaccination scheme, a reduction in the number of doses during intramuscular as well as subcutaneous vaccination by AVA vaccine has been tried in studying immunogenicity in the framework of the US Military Anthrax Vaccine Immunization Program. Levels of antibodies ( $\mathrm{IgG}$ ) in the routine scheme $(\mathrm{n}=28)$ and a changed scheme $(n=22)$ in vaccinated persons were approximately the same. ${ }^{19}$ In January 2002, the Department of Defense did not recommend vaccination of women due to insufficient data about the possibility of an increased risk for birth defects. ${ }^{26}$

Some experts presume that the reported data on adverse reactions are not objective because vaccinated persons have a negative reaction not reflected in adverse event reports. Therefore, the literature may not sufficiently present the real range of adverse reactions. Continuing observation of adverse reactions after vaccination is critical. The evaluation of a vaccine-related syndrome requires objective registration and data reporting from a large number of vaccinated persons. It is also necessary to evaluate more than 10 million doses. ${ }^{19}$

\section{Development of New Vaccines}

Brossier et al. published experimental results that showed that adding formalin-inactivated anthrax spores (FIS) to protective antigen (PA) significantly reinforces the protection against anthrax infection in mice and guinea pigs. ${ }^{29}$ Nowadays, this strategy is used to prepare vaccines for animal immunization. Immunization with a vaccine containing FIS + PA has a synergic effect, stimulating protective immunity against toxaemia and the effects of infection. This information is promising for the construction of a new anthrax subunit vaccine for human use. Researchers are developing new vaccines inlcuding a recombinant live composed of a vaccine PA plus Salmonella PA protective antigen, a recombinant subunit vaccine composed of protective antigen expressed by Bacillus subtilis with various adjuvants (Saponin, AL3+, Freund's, Saponin, Monophosphoryl lipid A), and vaccines that employ microencapsulation, a new generation of recombinant PA. ${ }^{30}$

\section{Post-exposure Prophylaxis}

Post-exposure prophylaxis against anthrax using chemoprophylactics is recommended after a detectable or highly probable exposure to $B$. anthracis spores. Such exposure may occur following a biological terrorist incident or laboratory accident. Not much is known about people who may have been exposed to large numbers of spores, such as those in post offices of government buildings during the recent attacks in New York. During the bioterrorist attack in October 2001, the recommended chemoprophylaxis was ciprofloxacin, doxycycline, or amoxicillin daily for 60 days. ${ }^{31}$ The duration of antibiotic therapy has not been exactly determined. Long-term prophylaxis requires knowledge of the prolonged latent period of spore germination.

Antibiotics are effective against the germinated form of $B$. anthracis, but not against spores resident in the organism after an inhalation exposure. Spores may persist in the lung tissue without germination for months, as confirmed in experiments with monkeys. ${ }^{10}$ The length of persistence of $B$. anthracis spores in the lung tissue of exposed persons is not 
known. The literature contains no information about simultaneous immunization and administration of antibiotics in persons exposed to anthrax spores. In post-exposure prophylaxis, it is possible to use the recombinant antibodies against anthrax toxin.

\section{Inhibitors of Anthrax Toxin}

Various factors make mass vaccination against anthrax impractical. The bacteria can be eradicated from the host by treatment with antibiotics, but because of the continuing effects of the toxin, such therapy is of little value once symptoms have become evident. Thus, a specific inhibitor of the effects of the toxin might prove a valuable adjunct to antibiotic therapy. Mourez et al. ${ }^{32}$ reported the designing and testing of a polyvalent inhibitor of anthrax toxin that binds to heptameric PA63 and blocks its interaction with EF and LF. From a phage-display library, ${ }^{33}$ they identified a dodecameric peptide that binds to PA63 and weakly inhibits its interaction with the enzymatic moieties of the toxin. When they linked covalently multiple copies of this peptide to a polyacrylamide backbone, they demonstrated that the resulting polyvalent molecule strongly inhibited ligand binding by PA63, and the effects of the toxin in cell culture and in an animal intoxication model. ${ }^{34}$

\section{Conclusion}

The pre-exposure vaccination of persons with anthrax vaccine is based upon critical evaluation of epidemiological exposure risk by means of $B$. anthracis spores. Until 11 September 2001, it was a matter of risk prevention against the lung or skin anthrax form in persons at risk (soldiers, laboratory workers, and some profession groups). After the terrorist attacks in New York, pre-exposure vaccination of not only military, but also civilians, was recommended in the US [35]. Administration of this vaccine is generally recommended in persons who are at risk of repeated spore exposure, including laboratory workers manipulating samples, and in persons who repeatedly enter possible contaminated areas after attacks. Pre-exposure vaccination is not recommended in persons not at risk of repeated aerosol exposure of $B$. anthracis spores in their occupation. In the prevention of morbidity and mortality connected with anthrax in the general population, fast detection, diagnosis, proper treatment, and post-exposure prophylaxis will always make a difference.

Current anthrax vaccines are not licensed for post-exposure use in preventing anthrax. Based on limited data from animal studies, post-exposure antimicrobial prophylaxis should last 60 days. Simultaneous administration of the vaccine and drugs could be advantageous, and allow for reduction of the long-termed antimicrobial treatment (60 days) with it consequent risk of possible adverse reactions.

The data for evaluating the duration of antimicrobial use in combination with vaccine for postexposure anthrax prophylaxis are insufficient. ${ }^{35}$ It was proved that within 14 days after the third dose of AVA vaccine, maximal titres of antibodies were recorded in vaccinated persons. Additional expanded animal studies are necessary to evaluate the further effectiveness of antimicrobial prophylaxis with and without anthrax vaccine for prevention of inhalation anthrax. 


\section{References}

1. Merka V, Patocka J. Anthrax: an important agent of biological terrorism. Nederl Milit Geneesk T. 2002;55:142-145.

2. Prymula R, Splino M, Chlibek R, Beran J, Fusek

J, Bajgar J. Biological and Chemical Terrorism.

Prague: Grada Publishing; 2002. (In Czech)

3. Splino M, Patocka J. Prophylaxis against anthrax. Acta Medica. 2002;45:85-88

4. Inglesby TV, Henderson DA, Bartlett JG et al. Anthrax as a biological weapon: medical and public health management. JAMA. 1999;281:1735-1745 5. Friedlander AM. Anthrax: clinical features, pathogenesis, and potential biological warfare threat. Curr Clin Top Infect Dis. 2000;20:335-349.

6. Zilinskas RA. Iraq's biological weapons. The past as future? JAMA. 1997;278:418-424.

7. CDC. Surveillance for adverse events associated with anthrax vaccination-U.S. Department of Defence, 1998-2000. MMWR. 2000;49:341-345.

8. Brachman PS. Inhalation anthrax. Ann $N$ Y Acad Sci. 1980;353:83-93.

9. Meselson M, Guillemin J, Hugh-Jones M, et al The Sverdlovsk anthrax outbreak of 1979. Science. 1994:266:1202-1208

10. Friedlander AM, Welkas SL, Pitt ML, et al Postexposure prophylaxis against experimental inhalation anthrax. J Infect Dis. 1993;167:1239-1243.

11. Sirard JC, Guidi-Rontani C, Fouet A, et al. Characterization of a plasmid region involved in Bacillus anthracis toxin production and pathogenesis. Int J Med Microbiol. 2000;290:313-316.

12. Lacy DB, Collier RJ. Structure and function of anthrax toxin. Curr Top Microbiol Immunol 2002;271:81-85.

13. Brossier F, Mock M. Toxins of Bacillus anthracis. Toxicon. 2001;39:1747-1755.

14. Bhatnagar R, Batra S. Anthrax toxin. Crit Rev Microbiol. 2001;27:167-200.

15. Mahlandt BG, Klein $F$, Lincoln RE et al. Immunologic studies of anthrax: IV. Evaluation of the immunogenicity of three components of anthrax toxin. J Immunol. 1966;96:727-733.

16. Wright GG, Green TW, Kanode RJ Jr. Studies on immunity in anthrax. V. Immunizing activity of alum-precipitated protective antigen. J Immunol. 1954:73:387-391.

17. Turnbull PCB, Broster MG, Carman JA, et al Development of antibodies to protective antigen and lethal factor components of anthrax toxin in humans and guinea pigs and their relevance to protective immunity. Infect Immun. 1986;52:356 363.

18. Brachman PS, Gold H, Plotkin SA et al. Field evaluation of a human anthrax vaccine. $A m \mathrm{~J}$ Public Health. 1962;52:632-645.

19. Sato PA Reed RJ, Smith TC, Wang L. Monitoring anthrax vaccine safety in US military service members on active duty: surveillance of 1998 hospitalizations in temporal association with anthrax immunization. Vaccine. 2002;20:2369-2374.

20. Chlibek R. BW Threat Reduction-Medica Prophylaxis. Proceedings of the Workshop on

Multinational Cooperation in Development of Mobile Biological and NBC Analytical Laboratories, Hradec Králové, Czech Republic, 2003.

21. Slyakhov EN, Rubinstein E. Human live anthrax vaccine in the former USSR. Vaccine. 1994; 12:727-729.

22. Ginsburg NN. Anthrax vaccine STI. Collected Works of the Red Army Institute of Epidemiology and Hygiene. 1946;1:5-90 (In Russian)

23. Alexandrov $\mathrm{NI}$, Gelen $\mathrm{NE}$, Garin NS, et al. Experience in massive aerogenic vaccination of humans against anthrax. Voen Med Zh. 1959;8: 27-32. (In Russian)

24. Brachman PS, Friedlander AM. Anthrax. In: Plotkin SA, Mortimer EA, eds. Vaccines. 2nd ed. PA: WB Saunders Company. 1994:729-793. 25. Chen RT, Rastogi SC, Mullen JR, et al. The Vaccine Adverse Event Reporting System (VAERS). Vaccine. 1994;12:542-550.

26. http://www.promedmail.org ProMED mail web site Anthrax Vaccine, safety and efficacy (2002).

27. Wasserman GM, Grabenstein JD, Pittman PR Rubertone MV, Gibbs PP, Wang LZ, Golder LG. Analysis of adverse events after anthrax immu- nization in US Army medical personnel. J Occup Environ Med. 2003 Mar;45(3):222-233.

28. lowa Persian Gulf Study Group. Self-reported illness and health status among Gulf War veterans: a population-based study. JAMA. 1997;277: 238-245.

29. Brossier F, Levy M, Mock M. Anthrax spores make an essential contribution to vaccine efficacy. Infect Immun. 2002;70:661-664.

30. Cuyck H. Brief report on the 4th Anthrax Conference, Annapolis, USA, June 2001.

31. CDC. Investigation of Bioterrorism-Related Anthrax and Interim Guidelines for Exposure Management and Antimicrobial Therapy, December 2000, MMWR. 2000;49:No RR15, 13-14, October 2001, MMWR. 2001;50:909-919, November 2002, MMWR., 51:No.45,1025.

32. Mourez M, Kane RS, Mogridge J, et al. Designing a polyvalent inhibitor of anthrax toxin. Nat Biotechnol. 2001;19:958-961.

33. Zwick MB, Shen J, Scott JK. Phage-displayed peptide libraries. Curr Opin Biotechnol. 1998; 9:427-435.

34. Seppa NN. New anthrax treatment works in rats. Science News. 2001;159:296.

35. $h$ ttp://www.cdc.gov/mmwr/preview/

mmwrhtml/ACIP website Use of Anthrax Vaccine in the United States (2002).

36. Lange JL, Lesikar SE, Rubertone MV, Brundage JF Comprehensive systematic surveillance for adverse effects of anthrax vaccine absorbed, US Armed Forces, 1998-2000. Vaccine 2003; 21:1620-1628.

37. Baillie L, Hebdon $\mathrm{R}$, Flick-Smith $\mathrm{H}$, Williamson $D$. Characterisation of the immune response to the UK human anthras vaccine. FEMS Immunol Med Microbiol. 2003;36:83-86.

38. Sever JL, Brenner Al, Gale AD, Lyle JM, Moulton LH, Ward BJ, West DJ. Safety of anthrax vaccine: an expanded review and evaluation of adverse events reported to the Vaccine Adverse Event Reporting System (VAERS). Pharmacoepidemiol Drug Saf. 2004;13:825-840. 